\title{
Proceeding
}

Supplementary Issue: Winter Conferences of Sports Science. Costa Blanca Sports Science Events, 24 April 2020. Alicante, Spain.

\section{The effective means of aquafitness in correction of mature women's functional state}

\author{
TATIANA VYSOTSKAYA 14 , TATIANA SHUTOVA, SERGEI GOLUBNICHY \\ Department of Physical Education, Plekhanov Russian University of Economics, Moscow, Russia
}

\begin{abstract}
Purpose: the search of the effective means of aquafitness for the correction of the functional state of women in the age of 35-45. Materials and methods: 1) theoretical analysis and consolidation of data of the scientific and methodological literature; 2) estimation techniques of the morphofunctional state; 3) bioimpedance analysis; 4) pedagogical testing; 5) expert assessment; 6) questionnaire survey; 7) pedagogical experiment; 8) methods of the mathematical statistics. Results: the experiment was implemented from 2016 to 2019.256 women, who were just starting to do aquafitness, took part in it. They were subdivided into two groups: control group (128 women) and experimental group (128 women). Examinees of the control group had 40-minute workout 3 times per week: twice a week - aqua aerobics and once - swimming. Examinees of the experimental group did aquafitness 3 times per week for 40 minutes according to our developed method of integrated use of aquafitness means. Unique water workout programs, nutritional recommendations and its control were developed for the experimental group. The aquafitness' effective means were combined by us in 9 workout programs, which were distributed throughout training courses of the women in the age of 35-45. Conclusion: During the pedagogical experiment, the effectiveness of the author's method was established, which was expressed by more significant positive changes in the results in the experimental group compared to the control group in terms of functional status, fat and muscle components of the body.

Keywords: Efficient exercises in water; Health; Women of 35-45 years old; Functional health state, technique.

\section{Cite this article as:}

Vysotskaya, T., Shutova, T., \& Golubnichy, S. (2020). The effective means of aquafitness in correction of mature women's functional state. Journal of Human Sport and Exercise, 15(2proc), S189-S199. doi:https://doi.org/10.14198/jhse.2020.15.Proc2.09

Corresponding author. Department of Physical Education, Plekhanov Russian University of Economics, Moscow, Russia. https://orcid.org/0000-0002-2430-034

E-mail: golubnichaya2010@yandex.ru

Supplementary Issue: Winter Conferences of Sports Science. Costa Blanca Sports Science Events, 24 April 2020. Alicante, Spain.

JOURNAL OF HUMAN SPORT \& EXERCISE ISSN 1988-5202

(c) Faculty of Education. University of Alicante

doi:10.14198/jhse.2020.15.Proc2.09
\end{abstract}




\section{INTRODUCTION}

Considering global development of the society, a high social significance of the women's health should be noted. Women carry out cultural, educational, reproductive, productive and other functions. At the same time, it was discovered that $60 \%$ of women have disorders of the musculoskeletal system. $30-40 \%$ of Russian women experience high blood pressure, 30-50\% of women have excess body weight, $15-20 \%$ have joint diseases (Shutova et al., 2015; Shutova \& Pihaev, 2019). Consequently, the academy has started to pay attention to the search of the new approach of recreational workout reformation (Gorshkova, 2013; Kalischuk, 2018; Lanskaya et al., 2017).

Due to the decline of women's health and their physical state, aquafitness becomes the best possible recreational workout of aerobic orientation (Sharavieva et al., 2018; Dawson, 2017), especially for mature women. Workouts excel at a significant reduction in the strain on the joints and spine, normalization of blood pressure. Aquafitness gives an opportunity to do jumping, running exercises. It excels at reduction of body weight in the aquatic environment, reducing the likelihood of blood clots and varicosity (Vasilyeva, 1997; Voronchikhina, 2006; DeNysschen et al., 2018). Workouts in the water have a positive impact on activity of cardiovascular and respiratory systems. It can fairly help to reduce body weight and stem a spine problems risk.

Aquafitness workouts can be realized at the: 1) wellness centres; 2) public and commercial swimming pools; 3) healthcare facilities; 4) surface water; 5) homebased swimming pools; 6) swimming pools of any configuration at the facilities.

That is why practical significance of such workouts is increasing and it gives an opportunity to estimate effectiveness according to personal dynamics of each woman's functional state. However, repeated two- or three-time water workouts are not a guarantee of a reliable change in the functional development, women's morphofunctional state, their physical condition. Programs of comprehensive orientation, which control nutrition, age and level of physical condition, are not enough (Shutova, 2017; Ofei-Dodoo et al., 2018). Another problem is intermittent attendance on workouts, easy refusal to attend on them. The lack of need for regular classes among Russian women is mostly due to difficult social conditions. There is also a lack of attention to the individual characteristics of educates (Voronchikhina, 2006; Kaya et al., 2014).

Nowadays, the influence of the aquafitness on women's health is described in the works of Kolganova (2006), Gorshkova (2013), Busing \& West (2016). Innovational fitness-technologies in the water under conditions of physical education in Russia are showed in the works of Kazakova (2009), Kohan (2001). Scientific and theoretical fundamental concepts in waterobics are demonstrated in the works Polukhina (2003). The recreational kinds of gymnastics' and its fitness component's subject-matter in general is showed in the works of Cruz-Ferreira et al. (2015). Theoretical and methodological principles of swimming and described in the works of Karas (2006), innovational technologies with the use of water environment can be found in the works of DeNysschen et al. (2018), the complex usage of aquafitness' means is in the dissertation of Sharavieva (2018).

\section{Purpose}

The search of the effective means of aquafitness for the correction of the functional state of women in the age of $35-45$. 


\section{MATERIALS AND METHODS}

The methods: 1) theoretical analysis and consolidation of data of the scientific and methodological literature; 2) estimation techniques of the morphofunctional state; 3) bioimpedance analysis; 4) pedagogical testing; 5) expert assessment; 6) questionnaire survey; 7) pedagogical experiment; 8) methods of the mathematical statistics.

The experiment was held at the Tchaikovsky State Physical Education Institute (Chaykovsky, Russia). In addition, in Plekhanov Russian University of Economics (Moscow, Russia). The study was conducted from 2016 to 2019. 256 women who were starting aquafitness took part in the experiment. They were divided into two groups: a control group (128 persons) and an experimental group (128 persons). The persons of the control group were trained for 40 minutes 3 times a week: 2 times a week - water aerobics classes and 1 time a week - swimming. The persons of the experimental group were trained aquafitness for 40 minutes 3 times a week, following our technique of complex use of the aquafitness means. For the experimental group there were developed unique programs of activities in the water, recommendations on nutrition and control of it. The functional state was monitored: bioimpedance analysis (ABC-01 Medass), Omega diagnostics, Esteck System Complex - functional diagnostics, vital index, blood pressure, coefficients of cardiovascular system activity.

The guidelines to health-improving training of women $35-45$ of years old included the following: the average amplitude of the exercises performance, the average pace in the preparatory part of a training. Performance of a set of exercises in the main part of a training without additional support - 10-15 min. Control of breathing and heart beating, blood pressure and heart rate before, during and after the training. When performing a set of exercises in «deep» water, aqua-belts should be used. Freestyle swimming shall be performed with more time of swimming in fins. Using of fins allowed to reduce the load on the knee joint, to increase the speed of swimming, to improve the functional health state and physical preparation of women.

Special exercises for arms, back, legs, abdominal rectus and oblique muscles were performed in 3-4 sets of 8-30 repetitions. This helped to ensure efficient local action. Working at an average pace for a long time contributed to formation of endurance and correction of major muscle groups. In the preparatory part of the training the music tempo is $135-142 \mathrm{bpm}$. Indicators of heart rate should be within the range of 110-140 bpm in the preparatory part, $140-160 \mathrm{bpm}$ - in the main part and 110-125 bpm in the final part of the training (Sharavyeva et al., 2018).

The aquafitness means are classified according to: 1) the focus and effects produced on the body (development of physical qualities and movement coordination), 2) the effects produced on muscle groups, 3 ) the nature of motor activity; 4) the initial position; 5) the pace of exercises performance according to the music; 6) the using of equipment). The aquafitness means are combined into 9 training programs: Recreational Aquafitness, Functional Training, Running, Water Aerobics, Swimming and Strength, Perfect Legs, Super Abs, Deep Water, Interval Training. Practical implementation of the programs is provided in Table 1.

In the structure of the lesson, the following sequence of performing the exercises is recommended: preliminary stretching; elements of water aerobics for the upper free limbs belt, bows, turns $\rightarrow$ walking with high hips lifting $\rightarrow$ running exercises $\rightarrow$ swimming in various styles $\rightarrow$ learning series of exercises $\rightarrow$ jumping exercises $\rightarrow 5$ series of exercises (swimming and strength, water aerobics, interval training, super 
abs) $\rightarrow$ special exercises for certain muscle groups $\rightarrow$ swimming with various styles $\rightarrow$ exercises while standing at the side (swings, push-off, walking with high hips lifting); stretching, including on land.

Table 1. The integrated use of aquafitness' means.

\begin{tabular}{|c|c|c|}
\hline \multicolumn{3}{|c|}{ Training programs (preparatory part) } \\
\hline \multicolumn{3}{|c|}{ Week 1} \\
\hline Tuesday & Thursday & Saturday \\
\hline Swimming and Strength & Recreational Aquafitness & $\begin{array}{l}\text { Set at the "average" water depth } \\
\qquad(120-160 \mathrm{~cm})\end{array}$ \\
\hline \multicolumn{3}{|c|}{ Week 2} \\
\hline Tuesday & Thursday & Saturday \\
\hline Super-abs & $\begin{array}{c}\text { Perfect Legs + set at the } \\
\text { «average water» }\end{array}$ & Water Aerobics \\
\hline \multicolumn{3}{|c|}{ Week 3} \\
\hline Tuesday & Thursday & Saturday \\
\hline Recreational Aquafitness & Set at «deep water» & Swimming and Strength \\
\hline \multicolumn{3}{|c|}{ Week 4} \\
\hline Tuesday & Thursday & Saturday \\
\hline Super-abs + water aerobics & Running program & Recreational Aquafitness \\
\hline \multicolumn{3}{|c|}{ Week 5} \\
\hline Tuesday & Thursday & Saturday \\
\hline $\begin{array}{c}\text { Perfect Legs + recreational } \\
\text { aquafitness }\end{array}$ & Functional Training & Swimming and Strength \\
\hline \multicolumn{3}{|c|}{ Week 6} \\
\hline Tuesday & Thursday & Saturday \\
\hline Set at the «average water» & Interval training & Water Aerobics \\
\hline
\end{tabular}

The aquafitness means combined in the training programs are detailed in Table 2.

Table 2. Aquafitness' programs in the correction of the functional state of women.

\begin{tabular}{|l|l|}
\hline Running program & $\begin{array}{l}\text { Varieties of jumping over obstacles, forward jumping slide along the pool, imitation of } \\
\text { jumping over barriers, varieties of push-offs from the side of the pool, turning the body to } \\
\text { the right and left sides with support on the handrail, 2-3 series of swimming for 3-6 } \\
\text { minutes, arm-pumping exercises from the side of the pool. The tempo of the musical } \\
\text { accompaniment is average-90-120 accent/min and above average 120-130 accent/min. } \\
\text { Jumps with a 90-degree turn, "aqua-boxing" (imitation of kicks in boxing), imitation of kicks } \\
\text { in football, "aqua-jack" (jump - legs to the sides), "kick-boxing kicks", imitation of running } \\
\text { from prone lying position on the side, a pedometer from a prone lying position on stomach, } \\
\text { a set of running and jumping exercises with touching the bottom of the pool (5-10min), a } \\
\text { set of exercises for 32 counts on an aqua-step, a set of exercises in aqua-boots (32 counts } \\
\text {-2-3 raps). }\end{array}$ \\
\hline Water Aerobics & $\begin{array}{l}\text { A set of dance exercises for 32-64 counts, standing at the bottom of the pool. Sets with } \\
\text { martial arts elements, sets without touching the bottom of the pool. } \\
\text { The tempo of musical accompaniment is above average - 120-130 accent / min and high } \\
-130-147 \text { accent / min. Steps: mambo, kick, not up, launch in the jump, slide jump and } \\
\text { others. Jumps with a 90-degree turn, "scissors", exercise "butterfly" (jump - legs to the } \\
\text { sides), exercise "skier", imitation of kicks in football "aqua-jack", "pedometer" (at the same }\end{array}$ \\
\hline
\end{tabular}




\begin{tabular}{|c|c|}
\hline & $\begin{array}{l}\text { time one foot forward, the other back - high steps, without touching the bottom of the pool), } \\
\text { "kick boxing kicks". } \\
\text { Movement of the legs to the sides - body and legs bent, then the movements of the legs } \\
\text { to the sides are performed, circling of the lower leg in a sitting position - the legs bent at } \\
\text { an angle of } 90 \text { degrees, circling of the calf should be performed. "Fall overs" - body and } \\
\text { legs bent, then prone lying position, along the surface of the water, then again body and } \\
\text { legs bent and prone lying position on stomach, the next exercise of moving legs to the } \\
\text { sides with a } 180 \text { degree turn, circling of the calf in a sitting position, complex coordination } \\
\text { exercises for } 8 \text { counts, exercises with } 90,180,360 \text { degrees turns. }\end{array}$ \\
\hline $\begin{array}{l}\text { Swimming and } \\
\text { Strength }\end{array}$ & $\begin{array}{l}\text { Swimming with aqua-dumbbells, swimming the crawl in full coordination, breaststroke, } \\
\text { swimming with mono fins, a set of exercises with two pool noodles for } 32 \text { counts. A set of } \\
\text { exercises with aqua-boards, varieties of dumbbell flies, as well as varieties of the } \\
\text { dumbbells pushing back and forth, sideways, circling with dumbbells, imitation of stroke } \\
\text { movements with dumbbells. } \\
\text { The pace of music is above average - } 120-140 \text { accent/min. }\end{array}$ \\
\hline "Perfect Legs" & $\begin{array}{l}\text { Set of swimming in fins for } 10 \mathrm{~min} \text {. Imitation of jumps over barriers, varieties of } \\
\text { hydromassage exercises, a set of exercises without touching the bottom of the pool, } \\
\text { breaststroke } 50-100 \text { meters, side crawl with support on the pool noodles. } \\
\text { The tempo of musical accompaniment is above average - } 120-130 \text { accent/min and high } \\
130-140 \text { accent/min. } \\
\text { Imitation of kicks in football, flies in the preparatory sitting position, leg movements to the } \\
\text { sides (body and legs bent, then leg movements to the sides are performed), leg } \\
\text { movements to the sides with } 180 \text { degree turn, "aqua-jack", "kicks of kick-boxing "," } \\
\text { hydromassage of calf ". Water aerobics exercise set for } 5-15 \text { min. }\end{array}$ \\
\hline "Super- abs" & $\begin{array}{l}\text { From a vertical position of the body, jump into a tuck, then raise your legs at an angle of } \\
90 \text { degrees. Backstroke in flippers ("wave"), swimming in flippers on the side (wave, } \\
\text { crawl). The tempo of musical accompaniment: } 125-140 \text { accent/min. } \\
\text { Mixing and raising legs in the sitting position. Circular movements of the lower leg in a } \\
\text { sitting position (legs bent at an angle of } 90 \text { degrees, circular movements of the lower leg } \\
\text { should be performed). "Coups" - tuck, then assume a supine position along the surface } \\
\text { of the water, then again the position of the constellation and turns over to the supine } \\
\text { position. Movement of the legs to the side with a rotation of } 180 \text { degrees. Circular } \\
\text { movements of the lower leg in a sitting position. } \\
\text { Flexion and extension of the legs in the floor in sitting position, legs are on the parallel to } \\
\text { the surface of the water. Movement of the legs to the sides and "to the cross" in front of } \\
\text { you, from the starting position of sitting. Jumping "fold" from the vertical position of the } \\
\text { body, to an angle of } 90 \text { degrees to raise legs in a jump. }\end{array}$ \\
\hline $\begin{array}{l}\text { Deep water } 160- \\
200 \mathrm{~cm}\end{array}$ & $\begin{array}{l}\text { Complexes with noodles without touching the bottom of the pool, a series of water } \\
\text { aerobics exercises for } 10-13 \text { minutes. Varieties of stroke movements in place in motion } \\
\text { with turns. } \\
\text { The tempo of the musical accompaniment: } 130-143 \text { accent / min. } \\
\text { "Aqua-jack", "pedometer" (at the same time one foot forward and the other back - high } \\
\text { steps, without swinging the bottom of the pool). "Slender waist" (tilt to the sides with unlike } \\
\text { lifting of the legs to the side), "hydromassage of the lower leg". Circular movements of the } \\
\text { lower leg in a sitting position - legs bent at an angle of } 90 \text { degrees, circular movements of } \\
\text { the lower leg should be performed. Movement of the legs to the side with a rotation of } 180 \\
\text { degrees. Circular movements of the lower leg in a sitting position. }\end{array}$ \\
\hline
\end{tabular}




\section{RESULTS}

The results of forming pedagogical experiment (Table 3) showed statistically significant health-improving changes in the functional health state and the component structure of the women's bodies in the experimental group, as compared to the control one.

Table 3. Dynamics of indicators of the functional state and component composition of the body of women 3545 years old, $\bar{x} \pm \sigma$.

\begin{tabular}{|c|c|c|c|c|c|c|}
\hline \multirow{2}{*}{\multicolumn{2}{|c|}{ Indicators }} & \multirow{2}{*}{ Groups } & \multicolumn{4}{|c|}{ Experimental period } \\
\hline & & & $2013 y r$. & 2014 yr. & $2015 \mathrm{yr}$. & $2016 y r$. \\
\hline \multirow{2}{*}{\multicolumn{2}{|c|}{ Height. cm }} & $E G$ & $164.5 \pm 3.8$ & $164.5 \pm 3.6$ & $164.5 \pm 3.6$ & $164.5 \pm 3.5$ \\
\hline & & CG & $165.9 \pm 4.1$ & $165.9 \pm 3.1$ & $165.9 \pm 4.1$ & $165.9 \pm 4.1$ \\
\hline \multirow{2}{*}{\multicolumn{2}{|c|}{ Weight. kg }} & EG & $75.3 \pm 3.9$ & $70.4 \pm 2.8$ & $68.2 \pm 3.8^{*}$ & $64.1 \pm 2.8^{\star *}$ \\
\hline & & CG & $75.5 \pm 2.9$ & $73.4 \pm 3.4$ & $71.6 \pm 4.6$ & $70.3 \pm 2.8^{\star * \star}$ \\
\hline \multirow{4}{*}{ Dynamometry. kg } & \multirow{4}{*}{$\begin{array}{l}\text { Right } \\
\text { hand } \\
\text { Left } \\
\text { hand }\end{array}$} & EG & $29.0 \pm 1.9$ & $31.1 \pm 1.8$ & $32.5 \pm 2.7$ & $33.4 \pm 1.6^{* *}$ \\
\hline & & CG & $28.7 \pm 1.9$ & $29.0 \pm 2.1$ & $30.1 \pm 1.9$ & $30.8 \pm 1.7$ \\
\hline & & EG & $25.3 \pm 1.8$ & $26.6 \pm 1.7$ & $28.4 \pm 1.7$ & $29.1 \pm 2.3$ \\
\hline & & CG & $25.6 \pm 1.9$ & $26.2 \pm 2.2$ & $26.9 \pm 1.8$ & $27.4 \pm 2.6$ \\
\hline \multirow{2}{*}{\multicolumn{2}{|c|}{ Bust. cm }} & EG & $108.3 \pm 5.5$ & $101.5 \pm 4.4$ & $98.6 \pm 3.3^{*}$ & $94.0 \pm 2.2^{* *}$ \\
\hline & & CG & $106.4 \pm 6.4$ & $104.0 \pm 5.3$ & $102.1 \pm 5.3$ & $100.5 \pm 2.3^{\star \star \star}$ \\
\hline \multirow{2}{*}{\multicolumn{2}{|c|}{ Waist. cm }} & EG & $94.7 \pm 5.0$ & $90.8 \pm 3.7$ & $87.4 \pm 2.7$ & $81.0 \pm 2.5^{\star *}$ \\
\hline & & CG & $96.1 \pm 5.9$ & $93.1 \pm 3.9$ & $89.5 \pm 2.7$ & $86.2 \pm 2.6^{\star \star \star}$ \\
\hline \multirow{2}{*}{\multicolumn{2}{|c|}{ Hips. cm }} & EG & $113.9 \pm 4.6$ & $108.6 \pm 3.7$ & $103.9 \pm 3.2^{*}$ & $99.2 \pm 2.3^{* *}$ \\
\hline & & $C G$ & $111.6 \pm 4.9$ & $109.1 \pm 3.1$ & $106.6 \pm 2.1$ & $104.2 \pm 2.4^{\star \star \star}$ \\
\hline \multirow{2}{*}{\multicolumn{2}{|c|}{ Excursion of the chest circumference. $\mathrm{cm}$}} & EG & $3.2 \pm 2.3$ & $4.9 \pm 2.1$ & $5.8 \pm 1.9$ & $7.0 \pm 1.0^{* *}$ \\
\hline & & CG & $3.3 \pm 2.8$ & $4.2 \pm 2.5$ & $4.9 \pm 1.9$ & $5.4 \pm 1.4^{* *}$ \\
\hline \multirow{2}{*}{\multicolumn{2}{|c|}{ Fat component. \% }} & EG & $39.0 \pm 1.5$ & $32.4 \pm 1.5^{*}$ & $28.4 \pm 1.4^{*}$ & $26.5 \pm 1.3^{* *}$ \\
\hline & & CG & $38.7 \pm 1.5$ & $36.2 \pm 1.9$ & $33.9 \pm 1.7^{\star \star \star}$ & $31.1 \pm 1.4^{\star * *}$ \\
\hline \multirow{2}{*}{\multicolumn{2}{|c|}{ Muscle component. \% }} & EG & $28.4 \pm 3.1$ & $33.6 \pm 2.0$ & $34.2 \pm 3.0$ & $36.3 \pm 2.0^{* *}$ \\
\hline & & CG & $28.8 \pm 3.9$ & $30.6 \pm 3.4$ & $32.7 \pm 1.8$ & $33.4 \pm 1.9^{\star \star \star}$ \\
\hline \multirow{2}{*}{\multicolumn{2}{|c|}{ Water fraction. \% }} & EG & $40.9 \pm 2.0$ & $48.4 \pm 2.1^{*}$ & $51.3 \pm 1.8$ & $55.4 \pm 1.9^{* *}$ \\
\hline & & CG & $43.9 \pm 1.6$ & $45.3 \pm 1.6$ & $46.9 \pm 1.6$ & $49.3 \pm 1.6^{* * *}$ \\
\hline \multirow{2}{*}{\multicolumn{2}{|c|}{ Visceral fat. \% }} & EG & $11.5 \pm 1.5$ & $10.1 \pm 1.8$ & $9.2 \pm 1.4$ & $7.5 \pm 1.3^{* *}$ \\
\hline & & CG & $10.9 \pm 1.6$ & $10.0 \pm 1.5$ & $9.3 \pm 1.5$ & $8.9 \pm 1.4$ \\
\hline
\end{tabular}

Note: $\square$ - indicators are normal, $\square$ - indicators are below the norm, $\square$ - indicators are above the norm, ${ }^{*}-$ significance of differences $(p<.05),{ }^{* *}-$ final significance of differences $(p<.05)$, ${ }^{* * *}-$ intergroup significance of differences $(p<.05), C G-$ control group, $E G$ - experimental group.

Using of aquafitness means in the experimental work, with regard to the age features of women, allowed to greatly improve the performance of the functional health state of cardiovascular and respiratory systems of their bodies (Table 4).

The coefficient of efficiency of blood circulation (Table 4) represents the cost of the body for blood movement in the bloodstream. The coefficient indicates the quantity (volume) of blood that is ejected from the left ventricle per one tick of the blood. Normally, the value of the coefficient is 2600 c. u., and, in case of disorders, it increases up to $4000 \mathrm{c}$. u.

The results of this indicator in the studied groups at the beginning of the experiment did not meet the standard (2600 c. u.) and were 4292 c. u. (above the standard) and 4199.9 c. u. (above the standard), respectively, in the experimental and control groups. Increase of the coefficient indicates the central blood circulation rearrangement, which is associated with increased expenditure of body reserves. 
Table 4. Dynamics of indicators of the functional state of the cardiovascular and respiratory systems of women $35-45$ years, $\bar{x} \pm \sigma$

\begin{tabular}{|c|c|c|c|c|c|c|}
\hline \multirow{2}{*}{\multicolumn{2}{|c|}{ Indicators (norm) }} & \multirow{2}{*}{ Groups } & \multicolumn{4}{|c|}{ Experimental period } \\
\hline & & & $2016 \mathrm{yr}$. & $2017 \mathrm{yr}$. & $2018 \mathrm{yr}$. & $2019 \mathrm{yr}$. \\
\hline \multicolumn{2}{|l|}{1} & 2 & 3 & 4 & 5 & 6 \\
\hline \multirow{2}{*}{\multicolumn{2}{|c|}{ Lung capacity. ml }} & EG & $2475.0 \pm 178.3$ & $2865.0 \pm 163.6$ & $3275.0 \pm 135.7^{*}$ & $3545.0 \pm 105.2^{* *}$ \\
\hline & & CG & $2550 \pm 187.1$ & $2765.0 \pm 184.6$ & $2995.0 \pm 152.3^{*}$ & $3155.0 \pm 132.3^{\star \star \star}$ \\
\hline \multirow{2}{*}{\multicolumn{2}{|c|}{$\begin{array}{l}\text { Cardiovascular stamina (16 conventional } \\
\text { units) }\end{array}$}} & EG & $23.6 \pm 1.7$ & $20.9 \pm 1.6$ & $19.1 \pm 1.6^{*}$ & $16.2 \pm 1.6^{* *}$ \\
\hline & & CG & $22.9 \pm 1.6$ & $20.5 \pm 1.4$ & $18.9 \pm 1.5^{*}$ & $17.0 \pm 1.4^{* \star *}$ \\
\hline \multirow{2}{*}{\multicolumn{2}{|c|}{$\begin{array}{l}\text { The coefficient of efficiency of blood } \\
\text { circulation ( } 2600 \text { conventional units) }\end{array}$}} & EG & $4292.0 \pm 548.8$ & $3479.3 \pm 489.0$ & $2965.7 \pm 368.9^{*}$ & $2677.3 \pm 278.7^{\star \star}$ \\
\hline & & CG & $4199.9 \pm 558.4$ & $3868.7 \pm 528.6$ & $3525.8 \pm 468.9$ & $3376.4 \pm 349.2^{* * *}$ \\
\hline \multirow{2}{*}{\multicolumn{2}{|c|}{ Index of life. ml/kg (53-61 ml/kg) }} & EG & $35.4 \pm 2.5$ & $41.2 \pm 2.5^{*}$ & $49.6 \pm 2.6^{*}$ & $55.2 \pm 2.3^{* *}$ \\
\hline & & CG & $35.2 \pm 2.4$ & $39.4 \pm 2.4$ & $42.7 \pm 2.5^{*}$ & $47.4 \pm 2.6^{* * *}$ \\
\hline \multirow{4}{*}{$\begin{array}{l}\text { Systolic blood pressure } \\
(\mathrm{mm} \mathrm{Hg})\end{array}$} & \multirow[b]{2}{*}{ At rest } & EG & $130.1 \pm 4.4$ & $126.4 \pm 5.1$ & $122.3 \pm 6.3$ & $121.3 \pm 3.5^{\star *}$ \\
\hline & & CG & $129.2 \pm 5.5$ & $126.6 \pm 4.3$ & $123.5 \pm 4.2$ & $122.1 \pm 4.3^{* *}$ \\
\hline & \multirow{2}{*}{ After workout } & EG & $123.3 \pm 5.3$ & $123.5 \pm 6.4$ & $131.3 \pm 6.7$ & $120.6 \pm 5.4$ \\
\hline & & CG & $124.4 \pm 6.5$ & $123.9 \pm 5.4$ & $121.5 \pm 8.3$ & $120.1 \pm 9.4$ \\
\hline \multirow{4}{*}{$\begin{array}{l}\text { Diastolic blood pressure } \\
(\mathrm{mm} \mathrm{Hg})\end{array}$} & \multirow{2}{*}{ At rest } & EG & $84.9 \pm 2.8$ & $85.4 \pm 2.6$ & $80.7 \pm 2.5$ & $81.4 \pm 2.6$ \\
\hline & & CG & $86.0 \pm 2.8$ & $85.3 \pm 2.5$ & $87.4 \pm 2.6$ & $86.8 \pm 2.5$ \\
\hline & \multirow{2}{*}{ After workout } & EG & $77.7 \pm 6.6$ & $79.3 \pm 2.6$ & $81.5 \pm 3.5$ & $80.1 \pm 6.1$ \\
\hline & & CG & $79.4 \pm 4.5$ & $80.7 \pm 6.5$ & $82.5 \pm 4.2$ & $82.4 \pm 5.2$ \\
\hline \multirow{4}{*}{ Heart rate (beats/min) } & \multirow[b]{2}{*}{ At rest } & EG & $90.7 \pm 6.4$ & $87.4 \pm 5.5$ & $79.5 \pm 6.3$ & $72.2 \pm 4.1^{\text {** }}$ \\
\hline & & CG & $89.1 \pm 7.7$ & $80.7 \pm 5.6$ & $77.2 \pm 4.5$ & $73.5 \pm 9.6^{* \star}$ \\
\hline & \multirow{2}{*}{ After workout } & EG & $88.1 \pm 8.0$ & $80.4 \pm 7.2$ & $81.1 \pm 8.0$ & $74.1 \pm 6.1^{* *}$ \\
\hline & & CG & $86.4 \pm 9.2$ & $81.8 \pm 9.0$ & $70.9 \pm 4.1$ & $76.3 \pm 7.1^{* *}$ \\
\hline
\end{tabular}

Note: $\square$ - indicators are normal, $\square$ - indicators are below the norm, $\square$ - indicators are above the norm, ${ }^{*}-$ significance of differences $(p<.05),{ }^{* *}-$ final significance of differences $(p<.05)$, ${ }^{* *}$ - intergroup significance of differences $(p<$ .05), $C G$ - control group, EG - experimental group.

During the experiment, in the experimental group the standard values for efficiency of blood circulation were achieved -2677.3 c. u. (standard), in the control group the significant improvement of the coefficient was observed as well -3376.4 c. u. (above the standard), the significant improvement of the indicator was already observed after the first year of study in the experimental groups, while the significance of intergroup differences were revealed in the results.

It should be noted that the optimal values of efficiency of blood circulation were achieved in the third year of regular aquafitness classes attending. Improving of the performance of the blood circulation system of women of 35-45 years old may be explained by the fact that in the training process the intensive functional exercise programs (water aerobics, Swimming and Strength, Perfect Legs, Super Abs) were used, the number of exercises performed using the interval method means was expanded, swimming means were increased (from 150-200 $\mathrm{m}$ to 400-600 metres per one training).

The vital index gives an indirect idea of the functional capabilities of the external respiratory system. Normally, in women who do not exercise, it is $53-61 \mathrm{ml} / \mathrm{kg}$, if the indicator is less, it may indicate a lack of vital capacity of the lungs, or excess body weight.

In all groups at baseline indicators of living index did not meet the norm (53 to $61 \mathrm{ml} / \mathrm{kg}$ ) and were as follows: in the experimental group $-35.4 \mathrm{ml} / \mathrm{kg}$ (below normal), in the control of $35.2 \mathrm{ml} / \mathrm{kg}$ (below normal). The largest increase in this indicator was observed in the first year of classes, while there were found inter-group differences in results $(p<.05)$. By the end of the experiment, the indicator corresponded to the norm only in 
the experimental group and was $55.2 \mathrm{ml} / \mathrm{kg}$ (normal), in the control group there were positive changes, but the indicators did not correspond to the norm - $47.4 \mathrm{ml} / \mathrm{kg}$ (below the norm). The obtained results confirm the positive impact of water programs and swimming on the functional capabilities of external respiration of women 35-45 years old, the inter-group differences in the results are significant $(p<.05)$.

\section{DISCUSSION}

According to of Romanenko (2013), water aerobics classes (water aerobics workouts) contributed to a significant change in anthropometric indicators: weight loss by $2 \%$, waist circumference by $3 \%$, hips by $3.2 \%$.

Researcher Voronchikhina (2006) notes that the termination of regular classes by 1.5 months is manifested in a decrease in the achieved level of fitness within $50 \%$ and requires significant temporary, energy and physical efforts to restore lost levels, instead of maintaining and improving the healing effect. After a break in regular classes, all indicators of physical development are significantly reduced by $2.2-17 \%$.

Water aerobics classes should be combined into blocks separated by swimming exercises, and comprehensive monitoring (biomedical and psychological-pedagogical methods) is mandatory during classes. Such approach will provide alternation of loading and rest, tension and relaxation of muscles, switching from acyclic activity on cyclic. The most effective are exercises in "deep water" $(160-200 \mathrm{~cm})$, which use rotations, swinging arms and legs, simulation exercises, varieties of running in place and with advancement, water aerobics (Sharavieva et al., 2018; Shutova, 2017).

Kashuba et al. (2019) presented a methodology for conducting hydroaerobics classes, which involves taking into account "the individual characteristics of the health status of women of the first and second adulthood (28-35, 36-55 years old), a targeted combination of exercises with different focuses." The author defines a rational sequence of exercises according to criteria such as rhythmic alternation of tension and relaxation of various muscle groups, a combination of cyclic and acyclic exercises of moderate power.

\section{CONCLUSIONS}

The pedagogical experiment proved the efficiency of the author's technique, which consisted in the more significant improvement of the results in the experimental group as compared to the control in terms of functional health state, fat and muscle body component. The training of women 35-45 years old 45 the amount of aerobics reduces, swimming in fins expands, exercises in "deep water" $(160-220 \mathrm{~cm})$ are performed with supporting equipment. The optimal conditioning training at this age will prevent worsening of functional health state of women in the coming years and will be preventive sports and recreation activities.

\section{CONFLICT OF INTEREST}

Authors state that there is no conflict of interest.

\section{REFERENCES}

Ashdown, S.P., \& Na, H. (2008). Comparison of 3-D Body Scan Data to Quantify Upper-Body Postural Variation in Older and Younger Women. Clothing and Textiles Research Journal, 26(4), 292-307. https://doi.org/10.1177/0887302X07309131 
Borodulin, K., Laatikainen, T., Lahti-Koski, M., Lakka, T. A., Laukkanen, R., Sarna, S., \& Jousilahti, P. (2005). Associations between estimated aerobic fitness and cardiovascular risk factors in adults with different levels of abdominal obesity. European Journal of Cardiovascular Prevention \& Rehabilitation, 12(2), 126-131. https://doi.org/10.1097/01.hjr.0000164689.12082.e3

Busing, K., \& West, C. (2016). Determining the Relationship Between Physical Fitness, Gender, and Life Satisfaction. SAGE Open. https://doi.org/10.1177/2158244016669974

Cruz-Ferreira, A., Marmeleira, J., Formigo, A., Gomes, D., \& Fernandes, J. (2015). Creative Dance Improves Physical Fitness and Life Satisfaction in Older Women. Research on Aging, 37(8), 837855. https://doi.org/10.1177/0164027514568103

Dawson, M.C. (2017). CrossFit: Fitness cult or reinventive institution? International Review for the Sociology of Sport, 52(3), 361-379. https://doi.org/10.1177/1012690215591793

Duncan, M.C., \& Klos, L.A. (2014). Paradoxes of the Flesh: Emotion and Contradiction in Fitness/Beauty Magazine Discourse. Journal of Sport and Social Issues, 38(3), 245-262. https://doi.org/10.1177/0193723512467190

DeNysschen, C.A., Cardina, C., Sobol, J.J., Zimmerman, B., \& Gavronsky, A. (2018). Health, wellness, and fitness training: A pilot study on preparing physically fit and police academy-ready graduates. International Journal of Police Science \& Management, 20(1), 66-79. https://doi.org/10.1177/1461355718756412

Galeeva, O.B. (1997). Wellness practice of women 18-35 years dealing with hydroaerobic (dissertation). Omsk: Siberian state Academy of physical culture [in Russia].

Gorshkova, A.N. (2013). Technology of improving water aerobics classes with women 36-45 years (dissertation). Chelyabinsk: Ural state University of physical culture [in Russia].

Kalischuk, A.Yu. (2018). Positive influence of aquafitness on human health. Actual scientific researches in the modern world, 2-8 (34), 108-113 [in Russia].

Kashuba, V., Andrieieva, O., Goncharova, N., Kyrychenko, V., Karp, I., Lopatskyi, S., \& Kolos, M. (2019). Physical activity for prevention and correction of postural abnormalities in young women. Journal of Physical Education and Sport, 19(2), 500-506. https://doi.org/10.7752/jpes.2019.s2073

Karas, T.Yu. (2006). Method of improvement of students of preparatory medical group of institutions of secondary vocational education with the use of swimming facilities (dissertation). Khabarovsk: Far Eastern state Academy of physical culture [in Russia].

Kazakova, N.A. (2009). Improving physical fitness of girls aged 17-19 years on the basis of aqua aerobics (dissertation). Tchaikovsky: Tchaikovsky state Institute of physical culture [in Russia].

Kashuba, V., Andrieieva, O., Goncharova, N., Kyrychenko, V., Karp, I., Lopatskyi, S., \& Kolos, M. (2019). Physical activity for prevention and correction of postural abnormalities in young women. Journal of Physical Education and Sport, 19(2), 500-506. https://doi.org/10.7752/jpes.2019.s2073

Kaya, D.Ö., \& Çelenay, Ş.T. (2014). Health-Related Physical Fitness Profiles of Women who Attend Regular Activity Classes. Orthopaedic Journal of Sports Medicine. https://doi.org/10.1177/2325967114S00285

Kolganova, E.Yu. (2007). Influence of water aerobics classes on the state of the organism of women of different ages (dissertation). Malakhovka: Moscow state Academy of physical culture [in Russia].

Kokkinos, P. (2015). Physical Fitness Evaluation. American Journal of Lifestyle Medicine, 9(4), 308-317. https://doi.org/10.1177/1559827613520128

Kohan, T.A. (2001). The Use of hydroaerobic in physical education of students of technical University (dissertation). Omsk: Omsk state technical University [in Russia].

Krachler, B., Savonen, K., Komulainen, P., Hassinen, M., Lakka, T. A., \& Rauramaa, R. (2015). Cardiopulmonary fitness is a function of lean mass, not total body weight: The DR's EXTRA study. 
European Journal of Preventive Cardiology, 22(9), 1171-1179. https://doi.org/10.1177/2047487314557962

Lanskaya, O.V., Sazonova, L.A., \& Gerasimova, T.G. (2017). Aqua Aerobics as a means of rehabilitation of women 30-40 years with obesity I-II degree. Scientific Bulletin, 2 (12), 79-90 [in Russia].

McCabe, M.P., \& James, T. (2009). Strategies to Change Body Shape Among Men and Women Who Attend Fitness Centers. Asia Pacific Journal of Public Health, 21(3), 268-278. https://doi.org/10.1177/1010539509335498

Netz, Y., \& Raviv, S. (2002). Exercise, Fitness, and Subjective Measures Related to Fitness of Physical Education and other Teachers. Perceptual and Motor Skills, 94(3_suppl), 1091-1100. https://doi.org/10.2466/pms.2002.94.3c.1091

Ofei-Dodoo, S., Rogers, N.L., Morgan, A.L., Amini, S.B., Takeshima, N., \& Rogers, M.E. (2018). The Impact of an Active Lifestyle on the Functional Fitness Level of Older Women. Journal of Applied Gerontology, 37(6), 687-705. https://doi.org/10.1177/0733464816641390

Polukhina, T.G. (2003). Classification and typology of exercises in water aerobics as a basis for the development of training technology (dissertation). Moscow: Russian state University of physical culture, sports and tourism [in Russia].

Rodríguez-Cañamero, S., Gallardo, L., Luis Felipe, J., \& Garcíaunanue, J. (2018). Economic trend analysis of the fitness sector. Journal of Physical Education and Sport, 18(1), 79-88. https://doi.org/10.7752/jpes.2018.01010

Romanenko, N.I. (2013). The content of physical training of women 35-45 years using different types of fitness based on somatotype (dissertation). Krasnodar: Kuban state University physical culture, sporta and tourism [in Russia].

Rybakova, E., Shutova, T., \& Vysotskaya. T. (2020). Sports training of ski jumpers from a springboard based on body composition control and physical fitness. Journal of Physical Education and Sport, 20(2), 752-758. https://doi.org/10.7752/jpes.2020.02108

Rybakova, E.O., \&Shutova, T.N. (2017). Recreational competency of future bachelors of physical education. Teoriya I Praktika Fizicheskoy Kultury, 8, 15-17.

Sharavyeva, A.V., Shutova, T.N., Rybakova, E.O., \& Vozisova, M.A. (2018). Construction of recreational programs of aquafitness on the basis of synergetic and diversification approaches. Physical culture: education, training, 2, 23-25 [in Russia].

Shutova, T., \& Vysotskaya. T. (2019). Development of methods of population's physical training by using various types of fitness based on body composition's accounting. Journal of Human Sport and Exercise, 14(Proc4), 877-884. https://doi.org/10.14198/jhse.2019.14.proc4.50

Shutova, T.N. (2016). Aquafitness in the professional training of specialists in physical culture. Izvestia of the Tula state University. Physical culture. Sport, 3, 71-76 [in Russia].

Shutova, T.N., Rybakova, E.O., \& Sharavyeva, A.V. (2015). Correction of physical condition of women by means of aquafitness. Teoriya i Praktika Fizicheskoy Kultury, 1, 55-58.

Shutova, T.N., \& Pihaev R.R. (2019). Morphofunctional state of women of different age groups, beginning to engage in aquafitness. Scientific notes of the University. P.F. Lesgaft, 2 (168), 392-396 [in Russia].

Shutova, T.N. (2017). Modeling of fitness technologies in the process of physical education of students on the basis of diagnostics "esteck system complex". Teoriya i Praktika Fizicheskoy Kultury, 9, 3032.

Vasilyeva, I.A. (1997). Content and methods of water aerobics classes with mature women (dissertation). Moscow: Russian Academy of physical culture [in Russia].

Voronchikhina, I.A. (2006). Individual typological bases of water aerobics technique for mature age students (dissertation). Malakhovka: Moscow state Academy of physical culture [in Russia]. 
